ministry's old function as sponsor of a variety of industries from electronic computers to shipbuilding. The Aviation Group in the new ministry will be responsible for Concorde--part albatross and part eagleas well as for the ministry's task as supply agent for the Ministry of Defence. Mr Benn said this week that the creation of what is called a regional group within the ministry must be taken as a sign that there will be close collaboration with the new complex of ministries under Mr Anthony Crosland which is responsible, among other things, for regional planning and transport. The research group which has been created under the new arrangement is intended to be responsible for the ministry's experimental establishments and for its general support of industrial research. Within the ministry, the junior minister responsible for the research group will be Dr Ernest Davies, an able Member of Parliament who won a reputation for himself as an effective member of the House of Commons Select Committee on Science and Technology.

Mr Benn's deputy in the new department will be Mr Harold Lever, until now the chief assistant to the Chancellor of the Exchequer. Mr Lever, like Mr Benn, will remain a member of the Cabinet. Aviation will be dealt with by Lord Delacourt-Smith-a trade unionist who will also be responsible for putting some flesh on the bones of Mr Benn's hope that the new arrangement will allow trade unions to be involved in the making of industrial policy-and $\mathrm{Mr}$ Neil Carmichael. Mr Benn was at pains on Tuesday to explain how the new arrangement would make possible the abandonment of a good deal of the interdepartmental committee work which at present occupies the time of ministers and their helpers, but he was probably neither surprised nor offended that his proposals for the new ministry were greeted in the House of Commons by the complaint, from Sir Keith Joseph, that it would turn out to be too meddlesome. Time will no doubt tell.

\section{WILD LIFE}

\section{Birds' Death Unexplained}

NoBopy has yet explained why large numbers of dead seabirds are being washed ashore along the west coast of Britain. Speculation has abounded-a sudden food shortage, a virus epidemic, chemical pollution-but even the emaciated condition of many of the birds, which at first sight suggests starvation, gives no indication of whether they were first immobilized by a cause other than a lack of food.

Pathologists from the Ministry of Agriculture's Veterinary Laboratory at Lasswade, near Edinburgh, are looking for infective agents. In spite of the negative results so far, Dr A. R. Jennings of the Department of Animal Pathology, University of Cambridge, is also searching for signs of disease, and dead birds will also be sent to the National Institute for Medical Research at Mill Hill, in London, to test a theory that a virus of the influenza type may be responsible. One objection. to the theory that disease is responsible is that infections are usually limited to one species; the casualties so far include cormorants, gannets, guillemots, puffins, razorbills and shags.

Suggestions that there may have been a disruption of the food chain from algae to fish to birds are supported by reports that there were changes in the growth of plankton in the Irish Sea during the summer. A corollary is that there should be a scarcity of fish, the birds' main diet. Apparently the landings of sprats at Wexford have indeed been poor this year, but there is no other evidence of shortage. Much of the information about dead birds, especially in Cornwall, has come from fishermen, who have not remarked on any difficulties in their own job. The fact that dead seals have been found on Cornish beaches also suggests that shortages of food may not be an explanation; seals can often survive in conditions which starve other animals.

The notion that pollution of the sea may be responsibje has been considered at the Monks Wood Experimental Station of the Nature Conservancy. One dead guillemot has revealed abnormally large but sublethal quantities of a breakdown product of DDT and also of polychlorinated biphenyls which are formed as waste in the manufacture of plastics. There is, however, no sign of the shoals of dead fish expected after large-scale contamination. Guesses about leakage from wartime dumps of poison gas seem also to be unfounded.

Proposals that a freak coincidence of unfavourable conditions can explain the situation tend to look like the sort of all-embracing statement that can account for absolutely anything, yet it does seem that no simple theory is adequate. Dr N. W. Moore of Monks Wood noted that at this time of year some of the species are moulting and would be unable to fly out of a region with, for example, a poor food supply. These include guillemots and razorbills, which are among the worst affected. Further, in this state they could have been stranded by the unusually strong gales at the end of September, when the first deaths were noted. But these remain untested ideas, and Dr Moore emphasized that "we're all still groping in the dark". The only certainty is that, although the peak death rate is past, enough birds have died to endanger several of the species, which have not recovered from the effects of oil in the past two years.

\section{TELECOMMUNICATIONS}

\section{Below Three Millimetres}

Now that the Science Research Council has embraced the policy of increased emphasis on the practical applications of science, pensioners of the council have had to re-examine their priorities. At the Radio and Space Research Station which the council maintains near Slough, Bucks., and which held its open days this week, the change in emphasis has been achieved without fuss. On the pure science side, the station is continuing to be active in space research using rocket and satellite experiments and by helping research groups in the universities. But the station is stressing work going on which is aimed at extending the usable radio bands to higher frequencies, and thus relieving the pressure on the already overcrowded communication channels. And the interest which the station has always had in the physics of the ionosphere is now being presented from the point of view of its relevance to long distance communications.

At the high frequencies which may soon have to be pressed into use, corresponding to wavelengths of a few millimetres or less, the meteorological condition 
of the atmosphere becomes important. Radio links operating at slightly less than one centimetre wavelength are already coming into use in Britain, and the Radio and Space Research Station is intending to keep one jump ahead by investigating the effect of rain on transmissions at 3 millimetres and less. At 3 millimetres, for example, each millimetre of rain per hour attenuates the signal by between 0.5 and $1 \mathrm{~dB}$ per kilometre, but the station says that useful reliabilities can still be achieved over path lengths of a few

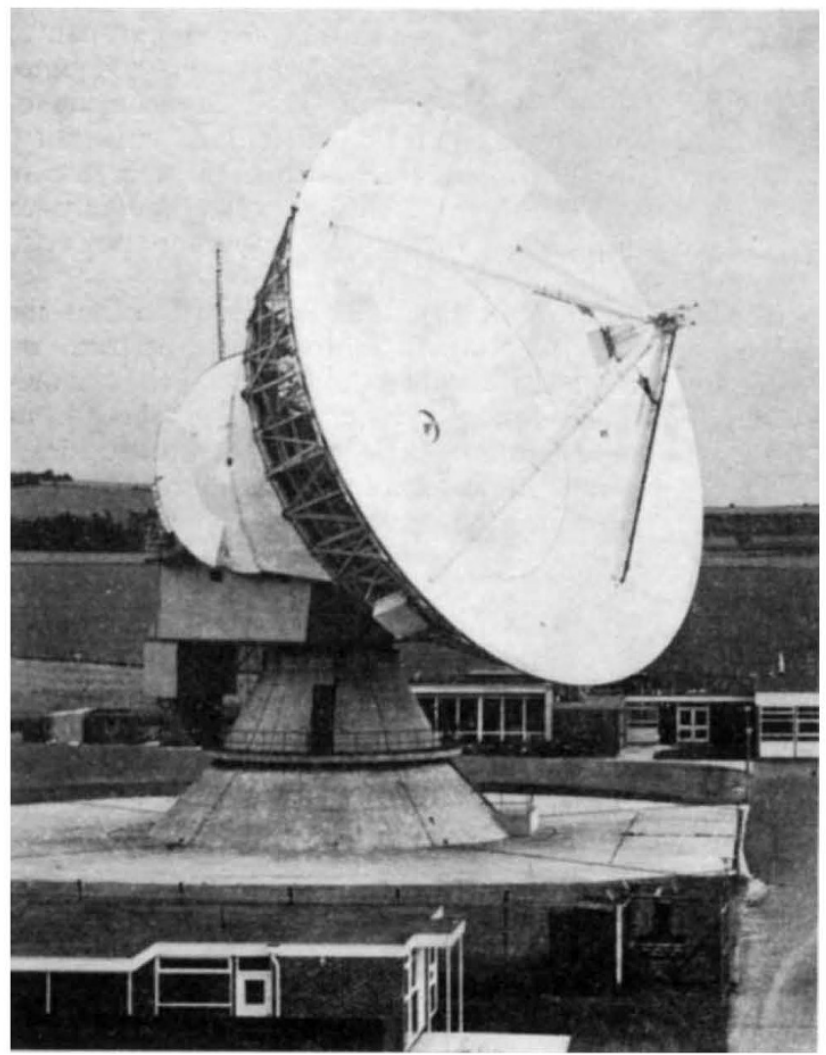

The Radio and Space Research Station operates a $25 \mathrm{~m}$ dish aerial at Chilbolton, Hampshire, which is used to investigate tropospheric and ionospheric effects on the transmission of radio waves. The aerial can be used down to $3 \mathrm{~cm}$.

kilometres. But it looks as if radio links at millimetre wavelengths are going to be limited to short paths or dry climates. The Radio and Space Research Station is also looking at the applications of short wavelengths to satellite communications by observing how centimetre waves from the Sun are affected by the atmosphere. Conversely, the station has been trying to interest the Meteorological Office in the use of short radio waves as an aid to meteorology, and there is a programme of laser sounding of the atmosphere.

\section{NUCLEAR REACTORS}

\section{Higher Temperafures Pay}

THe partiality of Sir Stanley Brown, chairman of the Central Electricity Generating Board, for high temperature gas cooled reactors has been a source of some controversy over the past year or so, both at the CEGB itself and among various factions of the nuclear

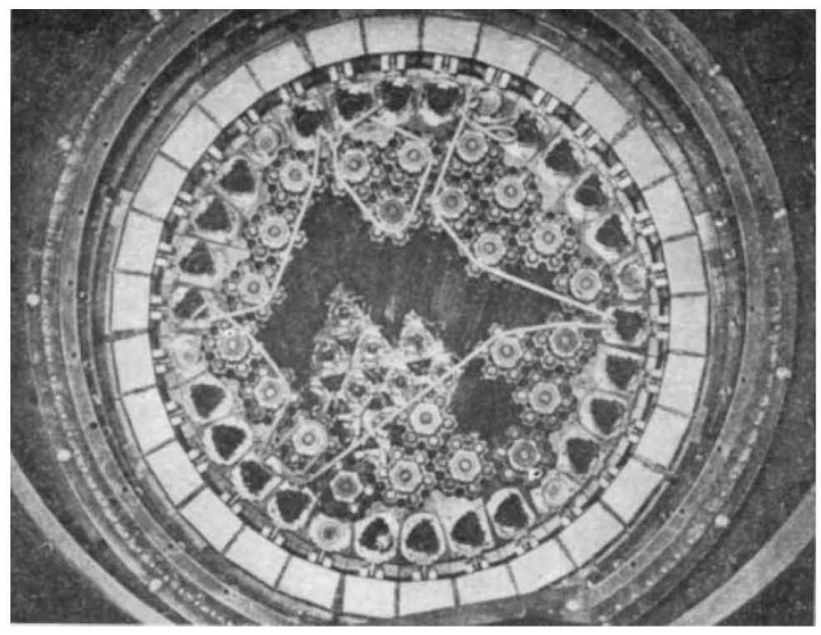

Partly loaded core of the Dragon reactor.

power industry. It was therefore no surprise that in a speech at the recent UNIPEDE conference in Zurich he had seized the opportunity of drawing attention to the advantages there would be if the Central Electricity Generating Board were to build high temperature reactors in the next few years.

Sir Stanley also had some kind words for the AEA's steam generating heavy water reactor. It is an attractive system, he said, with particular advantages in the lower megawatt ranges. The detailed engineering of the SGHWR is also better defined than that of the HTR. Nevertheless, for the CEGB, Sir Stanley said, high temperature reactors are likely to be economically superior, especially in large sizes. There was also the prospect of further saving from the use of still higher temperatures and even from the introduction of direct cycle gas turbines.

The widespread interest in the development of high temperature reactors in Europe seems to have created something of a bottleneck for testing facilities on the Dragon reactor. A meeting in London last week to plan the technical aspects of the future programme for the Dragon project was apparently overloaded with requests for irradiation space in the reactor for the testing of fuels up to full burn-up. The Dragon HTR reactor, with prismatic cores rather than sphere (or pebble) beds, is the only facility available for these tests. The $15 \mathrm{MW}$ reactor built by Brown Boveri at Julich in Germany is currently operational, but it is impossible to put test facilities into the pebble bed.

\section{BIOENGINEERING}

\section{Silicone Rubber for Membrane Lung}

THE development of safer and more compact heartlung machines is in sight as a result of the first production on a large scale of silicone rubber membranes. These "Silastofilm" membranes, said to be thinner and stronger than other types, were developed by Professor. Denis Melrose and Dr Nora Burns at the Royal Postgraduate Medical School at Hammersmith with the help of a grant from the National Research and Development Corporation.

Membranes offer the ideal solution to the problem of oxygenating blood in heart-lung machines without 